\title{
Malocclusion and Changes in Orofacial Motricity in Children Patients
}

\author{
Rebecca Maria da Paz de Queiroz Marques, Camylla de Albuquerque Felipe, Rafaella Vasconcelos Galvão, Pedro \\ José de Matos Neto, Júlia Damasceno Pompílio, Samuel Rodrigo de Andrade Veras, Sônia Maria Soares da Silva, \\ Leonardo Cavalcanti Bezerra dos Santos, Niedje Siqueira de Lima, Maria das Graças Duarte and Luciana de Barros \\ Correia Fontes*
}

Department of Clinical and Preventive Dentistry, Federal University of Pernambuco, Brazil

Received: 眥August 06, 2018; Published: 制 August 10, 2018

*Corresponding author: Luciana De Barros Correia Fontes, Department of Clinical and Preventive Dentistry, Federal University of Pernambuco, Rua Ester Foigel, ap. 1102, Iputinga 50721-440. Recife, Pernambuco, Brazil

\section{Abstract}

Introduction: Orofacial motricity is related to the functional and structural aspects of the orofacial and cervical regions, including the functions of the stomatognathic system. There is evidence on the possibility of alterations of the orofacial myofunctional and malocclusions.

Objective: to determine the frequency orofacial motricity alterations in children with malocclusion and also to verify the possible existence of association between these variables.

Methods: A cross-sectional study of the secondary data of children patients undergoing an extension program at the Federal University of Pernambuco, city of Recife, Brazil. Those of both sexes, aged between six and nine years, according to the inclusion criteria and attended between the years 2016 and 2017, in the actions of the Speech and Hearing and Dentistry team.

Results: Sample of 44 children, both gender, 56.8\% male, with a mean age of $7 \pm 08$ years old. The frequence of orofacial motricity alterations reached $61.4 \% ; 70.5 \%$ had deleterious oral habits and 54.5\% had non-ergonomic postural habits. There was a significant association between the presence of orofacial motricity alterations and Angle's Class II malocclusions, presence of anterior open bite and posterior crossbite $(p<0.05)$. Also between non-ergonomic postural habits and posterior crossbite $(p<0.05)$.

Conclusion: Changes in orofacial motricity were observed in more than half of the children's patients, and there was an association with some investigated malocclusions.

Keywords: Malocclusion; Mastication; Child Health Services; Orofacial Motricity; Harmful Oral Habits

\section{Introduction}

Malocclusion is a developmental disorder of the facial skeleton that affects different groups of muscles, such as facial expression, mastication and tongue muscles. It has a multifactorial origin which means that it can be caused by congenital, hereditary or local factors that have repercussions on the development of dental arches [1]. In addition to the problems related to the function, which are originated from morphological alterations, another relevant aspect that is also involved is the facial aesthetic, which causes psychological distress in those individuals who are affected with this condition [2]. According to data from the World Health Organization (WHO), malocclusion is the third complication of oral problems, following the top two which are tooth decay and periodontal disease. Furthermore, according to the National Research in oral health, SB Brazil 2010, nearly 25\% of the children by age 5 had one type of malocclusion, also the numbers keep increasing among older children. Thus, malocclusion represents a serious public health problem due to its high prevalence and negative impacts on the quality of life of those individuals who are affected with it [3].

Orofacial Motricity (OM) is related to the functional and structural aspects of the orofacial and cervical regions, including the functions of the stomatognathic system, such as suction, swallowing, chewing, breathing and articulation [4]. Due to the anatomical complexity of these muscular structures and because they are 
so closely connected, any alteration could cause disturbances, in both Speech Therapy and Dentistry areas, and those sequelae can affect functional and esthetic elements [5]. Studies have shown a high frequency of malocclusions and alterations in children which are related to orofacial motricity problems. These changes could be particularly associated with the presence of deleterious oral habits; which represents one of the most important risk factors for the development of malocclusion and cause damage to the phonoarticulatory organs, changing not only the functionality of mastication, but also speech and swallowing [6]. Therefore, despite the scientific evidence regarding the association between malocclusion and alterations in orofacial motricity, the amount of interdisciplinary studies on the subject is not sufficient. Consequently, it is very difficult to have a full understanding and specific approaches when treating the patients who have those problems. This study aims to determine the frequency of alterations in orofacial motricity of children with malocclusion, by verifying the possible association between these variables.

\section{Methods}

This research is linked to the activities of an Extension Program at the Federal University of Pernambuco, "Smiling in Family" (SOFA) city of Recife, northeast of Brazil, with interdisciplinary approaches to improve oral health for the children patients and their families (Dentistry, Law, Medicine, Occupational Therapy, Psychology, Social Assistance and Speech-Language). This study was approved by the Ethics in Research Committee of the Federal University of Pernambuco (CAAE 77741417.0.0000.5208). All the children patients that participated in the study were authorized by the parents and/or guardians through the signing of the consent form. For this study, 103 charts of children patients were taken in consideration. The age of the children ranged between six and nine, both genders were included. Those children attended the extension program from the second semester of 2016 until the first semester of 2017 (only regard the interdisciplinary actions between Speech Therapy and Dentistry). The inclusion criteria for the sample were defined according to the age, from six to nine years old, mixed dentition period, when the first permanent molars was erupted and the presence of any type of malocclusion. The records of children with neurological impairment, congenital defects or undergoing orthodontic or functional orthopedic treatment were excluded before the first evaluation.

The information was recorded during the anamnesis and physical examination of the children. The variables included in this study were: age, gender, disorders related to breathing, chewing, swallowing and phonation; the presence and classification of deleterious oral habits; presence and type of posture habit, presence and classification of malocclusions. Changes in orofacial motricity included morphological changes, decreased tension and altered movement of orofacial structures, and possible functional repercussions. The morphological aspects of face, lips, tongue, cheeks and occlusion, tension and mobility of the lips, tongue and cheeks were evaluated through clinical observation; counter- resistance tests with disposable wooden spatula and gloved finger to check the tension; mouth-to-smile movements, inflation and contraction of cheeks, tongue protrusion and retraction, and tongue movement towards the four cardinal points to verify mobility [7]. Problems related to breathing, chewing, swallowing, phonation, presence of deleterious oral habits and posture habits were considered. Changes in the occlusal normal pattern were considered according to the following orientations: anteroposterior, transverse and vertical. Patients were classified according to Angle criteria for the anteroposterior relationship between permanent first molars: Class I, Class II division 1, Class II division 2 and Class III. The presence of crossbite in the anterior regions (when it affected one or more anterior teeth) or posterior (when present in this region) was investigated. In this case, it was subdivided into bilateral (when present on right and left sides) or unilateral (when involving only one side). Regarding the vertical changes, it was established as a parameter of normality a vertical overpass not more than $50 \%$, which means that the upper permanent incisors should cover only half of the clinical crown of the lower permanent incisors. When the superior incisors covered greater than $50 \%$ of the inferior incisors it was categorized as overbite, on the other hand, the absence of vertical overpass it was categorized as open bite [8].

The gathered information was tabulated in the EXCEL worksheet. The data was analyzed descriptively through absolute frequency and percentage. It was applied the Pearson's Chi-square statistical test in order to evaluate the hypothesis of a significant association between two variables. When the investigated condition was not verified by using the chi-square test, it was used the Fisher's exact test. The margin of error used in the statistical test decisions was $5 \%$ and the statistical program used to obtain the statistical calculations was the SPSS (Statistical Package for the Social Sciences) version 23.

\section{Results}

For this study, 103 charts of children patients were taken in consideration, but after the analysis, only 44 (42.7\%) of those were selected. The sample was comprised of 44 infants of both genders, even though the number of male children represented $25(56.8 \%)$ of the participants, also the average of age was $7 \pm 8$ years. All children that participated in the actions of the Extension Program had malocclusions. According to Angle's Classification, the frequency of children with malocclusion Class I was 22 (50\%) of the subjects. Also, among the other types of vertical, transverse, and sagittal malocclusions, it was noticed that bilateral posterior crossbite was presented by $11(25.0 \%)$ individuals of the sample, as shown in Table 1 . This also presents a frequency of $27(61,4 \%)$ for alterations in Orofacial Motricity. Table 2 shows the distribution of patients according to changes in functional performance, presence of deleterious and postural oral habits. The data in this table show that the changes in respiratory pattern were more frequent among children with malocclusion 12 (27.3\%), 31 (70.5\%) with deleterious oral habits, especially digital sucking $9(20,5 \%)$ and 24 $(54.5 \%)$ with postural habits. 
Table 1: Distribution of assessed children patients, according to classification of malocclusion and presence of orofacial motricity alteration.

\begin{tabular}{|c|c|c|}
\hline Variable & $\mathbf{n}$ & $\%$ \\
\hline TOTAL & 44 & 100.0 \\
\hline Malocclusion & 44 & 100.0 \\
\hline \multicolumn{3}{|l|}{ Angle's classification } \\
\hline Class I & 22 & 50.0 \\
\hline Class II (1 $1^{\text {st }}$ division $)$ & 14 & 31.8 \\
\hline Class II ( $2^{\text {nd }}$ division $)$ & 5 & 11.4 \\
\hline Class III & 3 & 6.8 \\
\hline \multicolumn{3}{|l|}{ Other classification } \\
\hline Anterior open-bite & 7 & 15.9 \\
\hline Deep overbite & 8 & 18.2 \\
\hline Anterior crossbite & 5 & 11.4 \\
\hline Unilateral posterior crossbite & 9 & 20.4 \\
\hline Bilateral posterior crossbite & 11 & 25.0 \\
\hline Anterior primary crownding (upper or lower) & 4 & 9.1 \\
\hline $\begin{array}{c}\text { Orofacial motricity alteration } \\
\text { Yes } \\
\text { No }\end{array}$ & $\begin{array}{l}44 \\
27 \\
17\end{array}$ & $\begin{array}{c}100.0 \\
61.4 \\
38.6\end{array}$ \\
\hline
\end{tabular}

Table 2: Distribution of assessed children patients, according to changes in functional performance, deleterious oral habits and postural habits.

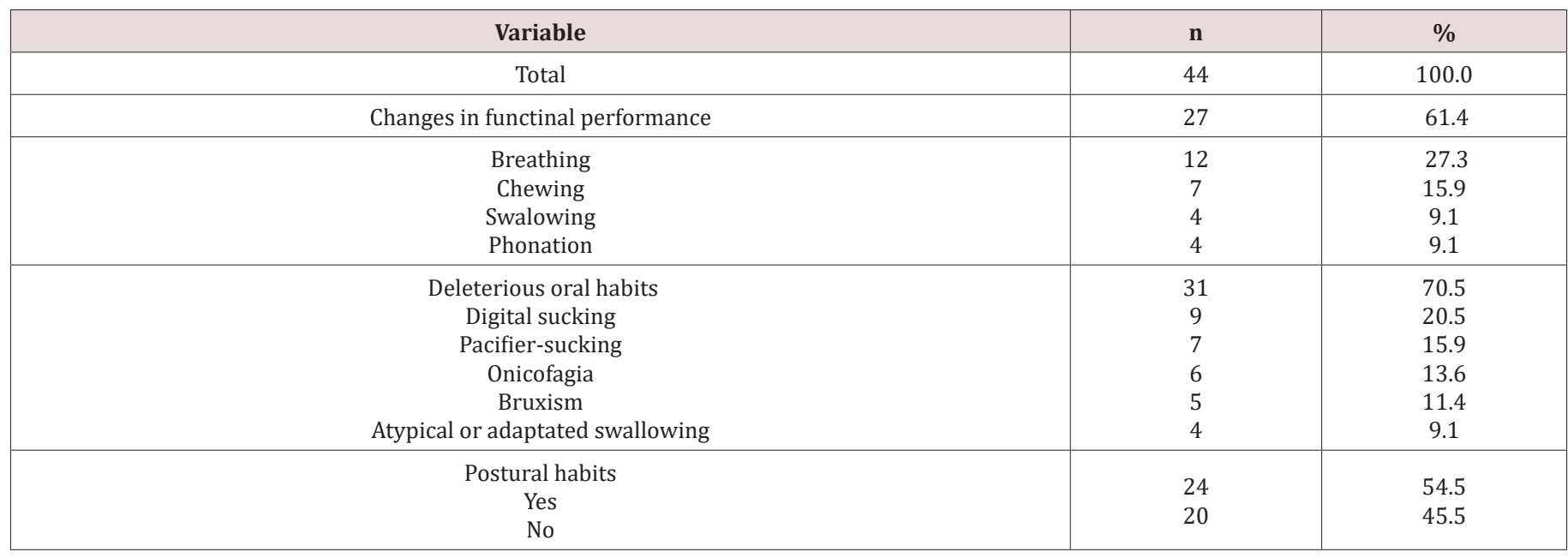

Table 3: Distribution of assessed children patients, according to malocclusion and orofacial motricity alteration.

\begin{tabular}{|c|c|c|c|c|c|c|c|}
\hline \multirow[t]{2}{*}{ Variable } & \multicolumn{2}{|c|}{ Yes } & \multicolumn{2}{|c|}{$\begin{array}{c}\text { Orofacial motricity } \\
\text { alteration } \\
\text { No }\end{array}$} & \multicolumn{2}{|c|}{ Total Group } & \multirow[t]{2}{*}{ p Value } \\
\hline & $\mathbf{n}$ & $\%$ & $\mathbf{n}$ & $\%$ & $\mathbf{n}$ & $\%$ & \\
\hline Total & 27 & 100 & 17 & 100 & 44 & 100 & \\
\hline \multicolumn{8}{|c|}{ Angle's classification } \\
\hline Class I & 8 & 50,0 & 2 & 18.2 & 14 & 35.3 & $\mathrm{p}^{(1)}<0.05^{*}$ \\
\hline Class II & 16 & 27.8 & 3 & 27.3 & 2 & 26.5 & \\
\hline \multicolumn{8}{|c|}{ Anterior open bite } \\
\hline Yes & 7 & 100 & - & - & 7 & 100 & $\mathrm{p}^{(1)}<0.001^{*}$ \\
\hline No & - & - & - & - & - & - & \\
\hline \multicolumn{8}{|c|}{ Deep overbite } \\
\hline Yes & 20 & 100 & - & - & 20 & 100 & $\mathrm{p}^{(1)}<0.001^{*}$ \\
\hline No & - & - & - & - & - & - & \\
\hline
\end{tabular}


Those last ones included, in descending order: the interposition of the lower lip and/or the tongue between the arches 12 (27.3\%), protraction of the mandible $7(15.9 \%)$ and support of the hand in the mandible 5 (11.3\%). Table 3 shows the significant changes ( $p$ $<0.05$ ) between the presence of alteration in the orofacial motricity and the type of malocclusion. It demonstrates a significant association between the presence of alterations in orofacial motricity and Angle's Class II malocclusions (when organized as Division I and II), anterior open bite and posterior crossbite ( $p$ $<0.05$ ), by grouping unilateral and bilateral posterior crossbite for this purpose. Despite the fact that all children with Angle's Class III malocclusion presented alteration in orofacial motricity, the test could not be established due to the low frequency of these cases, which were found only in 3 patients. Other possible associations were also tested, then it was seen a significant association between the presence of postural habits and the posterior crossbite; followed by the groups of unilateral and bilateral crossbite $(p<0.05)$. The study did not find any significant association regarding the age or gender of the participants ( $p>0.05)$.

\section{Discussion}

It has been very difficult to compare this study with others available in the literature. This might have happened due to the lack of studies regarding this content, mainly with the corroboration of both sciences, Dentistry and Speech Therapy, because of their differentiated methodology and approaches. This interaction allows understanding better the structures and dynamism of stomatognathic system as well as the guidelines for future researches. The methodology adopted in this research was based on a secondary data. The information gathered during the actions of the Extension Program was filed in order to be used as data for future projects. It is important to emphasize that, in this specific situation, one of the goals of the Extension Program is to do research, thus the data collected during the activities were already with this purpose. Moreover, the children's parents signed a Term of Free and Clarified Consent authorizing to use the information for future researches. The investigated sample was a representation of the appointments in the dental clinic, which represents almost half of the patients who were treated in the period considered for this research. It was possible to determine the frequency of orofacial motricity of those who had patients with malocclusions, seeking for a possible association between the variables. On the other hand, it is not possible to compare the children with or without malocclusion, because one of the inclusion criteria was to have any type of malocclusion [9].

Regarding the distribution of malocclusion in the children during the mixed dentition period, the authors recognize this period as the one with important dentoalveolar changes; thus great part of the occlusal problems can be perpetuated in the permanent dentition if no therapeutic conduct is performed as soon as possible, especially in situations of crossbite and open bite [10]. An epidemiological study developed in the city of Lins, State of São Paulo compared the distribution of these problems according to Angle's classification. The sample was comprised of 734 individuals by age 12 . The goal of this research was to evaluate the prevalence of malocclusions as well as the severity and the need of treatment [11]. The authors observed similar results in descending order of Class I, II and III malocclusions. They also found a higher percentage of Class I (55.92\%) and Class II (42.86\%), with lower Class III (1.22\%) as the present study.

When considering other classifications, the cross-bite has a higher frequency. A study [12] demonstrated the importance of early treatment of this common malocclusion in children's patients. The authors established that is necessary an adequate differential diagnosis regarding its etiology, skeletal, dental or functional impairment. This study also reinforces the high prevalence of unilateral posterior crossbite compared to bilateral; however this characteristic was not seen in this current research. Changes in orofacial motricity were found in the majority of the infantile patients of this study. However, it should be considered that the sample only included children with malocclusions, which could lead to a greater predisposition of disorders mainly in the specialty of Speech Therapy. A similar result was seen in other study, but with lower percentage. For this study, in the city of Santa Maria, Rio Grande do Sul, the authors investigated the presence of speechlanguage disorders in 262 schoolers aged from four to six years old. They also found a higher frequency of alterations in orofacial motricity (31.3\%), followed by alterations in speech $(21.37 \%)$ and language (4.58\%) [13].

These alterations can interfere in different ways, for example, the respiratory function can be altered by functional or organic factors. Thus, when the nasal breathing becomes mixed (nasal and oral) or predominantly oral, it becomes anti-physiological, which generates different compensatory changes. The presence of inappropriate postural habits, associated with oral breathing can lead to changes in growth and development of the face and teeth which are in formation. These changes lead to a change in the children's occlusion pattern and also interfere in the phonetic system [14]. The oral habits are strongly related to the presence of malocclusions, it means that they are a potential factor in the development of alterations of the structures and functions of the Stomatognathic System, depending on the intensity, frequency and duration of the stimulus, besides the genetic predisposition of the individual. In a literature review [15] regarding this content, the open bite was observed as the most associated malocclusion. This condition happens due to mechanical interposition between the upper and lower dental arches, usually by sucking a pacifier or finger. In this current study, postural habit was more frequent in children who grew up as oral breathers, so when the oral habits persist during the child's development it may provide a pattern of oral breathing, as was found in other studies $[6,16]$.

According to the consulted literature [17]. Regarding the deleterious oral habits, it was found a lower prevalence of digital 
sucking habits when compared to pacifiers; fact not observed in the present study. It was also noticed a controversy regarding the possibility of similar or greater damages caused by digital suction due to the difficulty of removing this habit. Despite scientific evidence of the association between malocclusion and changes in orofacial motricity, the number of interdisciplinary studies regarding this content is not enough, which explains the difficulty of understanding and having a consistent approach in terms of integral health care to these problems. Even with few articles regarding this content, most of those studies shown a significant improvement in relation to the treatment as well as in the patients' quality of life, if an early diagnosis and approach occur in the children. However, it is necessary to keep studying this content, not only seeking for an approach with methodological rigor but also comprising a more representative sample of the population so that the results can provide more conclusive information about this subject.

\section{Conclusion}

Changes in orofacial motricity were observed in more than half of the subjects, it was also noticed that oral breathing is the most frequent condition. It reinforces the need to integrate actions between Dentistry and Speech Therapy

\section{References}

1. Moreira AF, Pinto LS, Pinto K Von Ahn, Côrreia PG, Jeziorski SAZ, et al. (2015) Malocclusion impact on primary and permanente dentition in the quality of life of children and adolescents. Rev bras odontol 72(1/2): 70-75.

2. Sun L, Wong HM, McGrath CPJ (2018) Association between the severity of malocclusion, assessed occlusal índices, and oral related quality of ife: a systematic review and meta-analysis. Oral Health Prev Dent 16(3): 211-223.

3. Santos PM, Gonçalves AR, Marega T (2016) Validity of the psychosocial impact of Dental Aesthetics Questionnaire for use on Brazilian adolescentes. Dental Press J Orthod 21(3): 67-72.

4. Susanibar F, Santos R (2017) Marchesan International orofacial motricity day: Tongue-tie, affected oforacial functions. Rev CEFAC 19(1): 3-6.
5. Cavassani VGS, Ribeiro SG, Nemr NK, Greco AM, Köhle J, et. al (2003) Suction oral habits: initial study in low income population. Rev Bras Otorrinolaringol 69(1): 106-110.

6. Czlusniak GR, Carvalho FC, Oliveira JP (2008) Stomatognathic system disorders and the presence of sucking habits in children between 5 and 7 years of age: implications for speech and language interventions at school. Publ UEPG Ci Biol Saúde, Ponta Grossa 14(1): 29-39.

7. Rabelo ARV, Campos FR, Friche CP, Silva BSV, Friche AAL, et al. (2015) Speech and language disorders in children from public schools in Belo Horizonte. Rev Paul Pediatr 33(4): 453-459.

8. Bittencourt MAV, Machado AW. Bittencourt MAV, Machado AW (2010) An overview of the prevalence of malocclusion in 6 to 10-year-old children. Dental Press J Orthod 15(6): 113-122.

9. Souto RQ, Lucena B, Cavalcanti AL, França ISX (2011) Aspectos éticos na pesquisa com dados secundários: uma revisão sistemática. Revista Espaço para a Saúde, Londrina Dez 13(1): 45-53.

10. Mozeli KV, Negrete D (2015) Orthodontics in public health. Rev odontol. Univ Cid São Paulo 27(3): 229-234.

11. Garbin AJI, Perin PCP, Garbin CAS, Lolli LF (2010) Malocclusion prevalence and comparison between the Angle classification and the Dental Aesthetic Index in scholars in the interior of São Paulo state Brazil Dental Press J Orthod 15(4): 94-102.

12. Piña Luna I, Molinero Mourelle P, Torres Moreta L, Bartolomé Villar B (2016) Tratamiento precoz de la mordida cruzada posterior unilateral en el paciente infantil. Revisión bibliográfica. Cient dent 13(1): 41-48.

13. Angst OVM, Liberalesso KP, Wiethan FM, Mota HB (2015) Prevalence of speech-language disorders in kindergarten children of public schools and the social indicators. Rev CEFAC 17(3): 727-733.

14. Coelho PM, Silveira OS, Andrade ELSP, Vidigal BCL, Gome JM (2013) The importance of early diagnosis and intervention in the treatment of malocclusion in pediatric dentistry. Arq Bras Odontol 9(1): 14-18.

15. Imbaud TCS, Mallozi MC, Domingos VBTC, Solé D (2016) Frequency of rhinitis and orofacial disorders in patients with dental malocclusion. Rev Paul Pediatr 34(2): 184-188.

16. Rezende MS, Carvalho LC, Feliphe RAMP, Rocha CBJ, Silva VR, et al. (2016) Isostretching method effects on lung function and posture of mouth breathers. Conscientiae saúde 15(1): 89-95.

17. Boeck EM, Pizzol KEDC, Barbosa EGP, Pires NCA, Lunardi N (2013) Prevalence of malocclusion in 3 to 6 year-old sucking habit children Rev Odontol UNESP 42(2): 110-116.
This work is licensed under Creative Commons Attribution 4.0 License

To Submit Your Article Click Here: Submit Article
DOI: $10.32474 /$ MADOHC.2018.03.000154

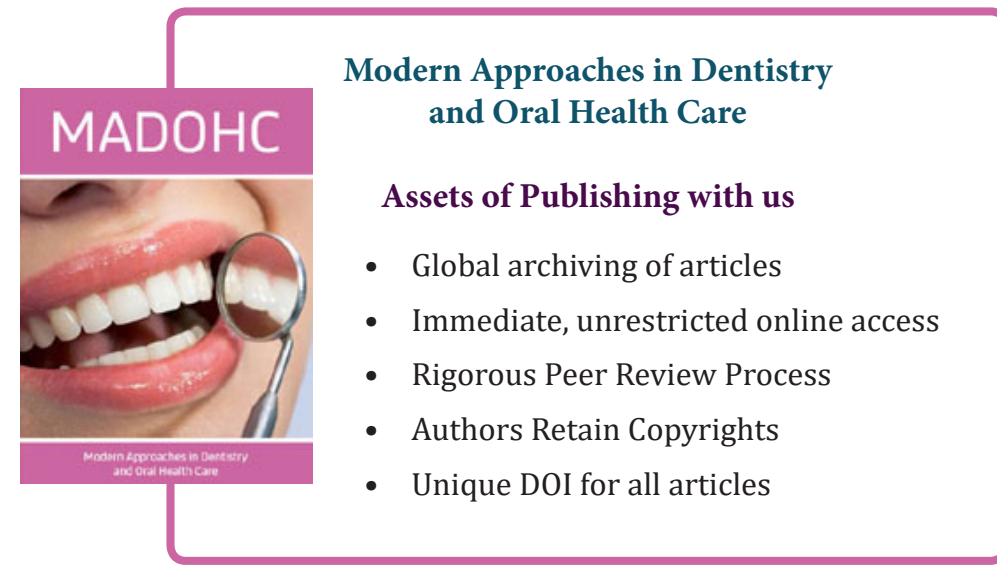

